\title{
Fostering Student Sensitivity to Diversity and Inclusion in Today's Classroom
}

\author{
Mikhail Beznosov \\ University of West Georgia
}

\author{
John P. Willerton \\ University of Arizona
}

Awareness, appreciation, and empathy for the diversity of groups, nations, and polities found in the contemporary nation-state system are core goals as today's students face the demanding policy agenda of the $21^{\text {st }}$ century.

Engaging diversity and fostering inclusion - across various dimensions (nationality-ethnicity, age, sex, gender, sexual orientation, religion, education, and socioeconomic development, among others - are critical to our teaching and mentoring goals. Operating in two very different university settings, and in different regions of the United States, we are political scientists interested in engaging different polities and societies to illuminate for our students challenges and opportunities around contemporary policy-making and governance. Both of us are comparativists, our professional interests are focused on Russia, Ukraine, and other former Soviet Union (FSU) countries, while we also bring knowledge of a variety of other nation-states (e.g., Sweden, France, Netherlands, Germany, Lebanon, Syria, Israel, India, Bhutan, and the United States) to our classrooms.

We use our classes (e.g., "The Politics of Happiness," "Diversity and Politics in a Changing World," "Russian Politics," "Global Issues," and "International Security Studies") to help students to develop cultural competency and the ability to function effectively in their society. It is also important to educate students on political and economic contexts in various societies. We want our students to be able to describe and analyze human behavior from different perspectives, varying from the societal, cultural, and historical, to institutional and individual perspectives. We want to broaden their understanding of diversity and global issues.

In our comparative cross-national focus, we understand diversity and inclusion to entail not just demographic criteria (e.g., ethnicity-race, sex, gender, and sexual orientation), but also values and beliefs (e.g., religion and ideology), developmental settings (e.g., pre-modern, modern, and post-modern), and the experiential (e.g., historical-experiential with age cohort).

We focus on a couple of techniques we have used to draw our (often diverse) student populations into our classroom inclusion socialization efforts: (1) an in-class (University of Arizona) application of Myers-Briggs [Personality] Test Indicator [MBTI] categories to a Native American policy case study, to help students better appreciate individual-level diversity and consequences for attitudes and policy preferences as they will subsequently move on to consider group-level diversity and challenges of inclusion; (2) an in-class course activity (University of West Georgia), with American and Ukrainian students' virtual participation in an international multidisciplinary conference organized by the School of Sociology (Kharkiv National University, Ukraine), to illuminate the payoffs of international student interaction; and (3) an active online discussion forum (University of West Georgia) linking American and Ukrainian 
students, as virtual sessions permitted students on either side of the Atlantic to draw on similar readings and YouTubes to simultaneously engage contemporary global issues.

We view these active, in-class, practices as fostering students' abilities to better appreciate diversity and the value of engagement and inclusion of "others." This is no less true of students engaging their diverse peers in their own classroom, as it is of students engaging their peers in other classrooms - and in other countries.

\section{Individual uniqueness, diversity, and inclusion: Using the MBTI Personality Test}

Issues of diversity and inclusion are complicated to tackle, albeit we operate in a time when we are generally sensitive to these issues. As with many American universities and political science departments, our University of Arizona School of Government and Public Policy has devoted growing attention to questions of diversity and inclusion, with the creation of a course, "Diversity and Politics in a Changing World" (Pol 209), yet a more recent effort. Developed as a Tier 2 General Education course (second-level Gen Ed course, targeted to sophomores or more advanced freshmen, but open to students of all levels - and all majors), the initial development and early offerings of "Diversity and Politics in a Changing World" are grounded in a comparative, cross-national focus. Students explore a diversity of polities (democratic and nondemocratic) that span four continents, with exposure to varied socioeconomic settings while explicitly drawing upon the experience of 12 countries. The generic Pol 209 course, however, is broadly defined to encompass various types of political settings and diversity-inclusion issues, including not only the comparative politics subfield, but also American politics, public policy, criminal justice, and international relations. Issues of diversity and challenges of inclusion can be meaningfully tackled in all of these subfields.

Here I discuss the initial two offerings of "Diversity and Politics in a Changing World" that are based on a discussion of various facets of diversity (e.g., race/ethnicity, gender, sexual orientation, religion, economic class, among other factors), with consideration of European, Middle Eastern, Asian, and North American polities. In challenging course participants to engage countries that are often subject to cartoon character stereotyping because they have been long perceived as cultural rivals or challengers to the United States, a desired goal is to move students outside the Anglo-American experience and values. Recalling that an early 2017 YouGov survey determined that Arabs, Muslims, and Russians account for 12 of the top 15 perceived nation-state-enemies of the U.S. as judged by Americans, nearly half of all class sessions focus on the countries of the Levant, Iran, and Russia. ${ }^{1}$ Accordingly, a major goal of this "Diversity and Politics" course is to make participants (1) more aware of, (2) more appreciative of, and - as is possible - (3) more empathetic to such perceived "enemy" nationstates. Indeed, a number of the countries examined in the class, judged by respondents in that

\footnotetext{
${ }^{1}$ The top 15 perceived enemy-states to the United States, according to surveyed Americans are, in order from 1 to 15: North Korea, Iran, Russia, Syria, Afghanistan, Libya, Iraq, Pakistan, Somalia, Palestinian Territory, Yemen, Sudan, Lebanon, South Sudan, and Cuba; YouGov survey, 28 January - 1 February 2017, N = 7150.
} 
same YouGov survey as being among the top 15 perceived "friends" of the United States, merit attention as they constitute value-policy "challenges" to American thinking and preferences. ${ }^{2}$

While the course focuses on 12 nation-states and the group (nation-state) level factors noted above, the desire to more intimately acclimate participants to diversity and inclusion issues results in an early-semester case study whereby participants briefly focus on individual-level diversity. The intention here is to encourage students to think about diversity first-hand, in their own life experience, as they consider important differences in individual personality that can have relevance to politics and one's life. This attention to individual-level diversity is accomplished by introducing each participant to the Myers-Briggs Test Indicator (MBTI), as students determine their own personality type taking the Myers-Briggs Personality Test. The MBTI is the mostly commonly used personality test in the United States, and while use of the MBTI is not without controversy, it serves our purposes in introducing students to issues of individual-level [personal] diversity, but as engaged in a more rigorous and systematic way. Students are first introduced, by a professionally trained MBTI specialist, to MBTI Theory and Personality Inventory (with 16 basic types). With a very basic awareness of complex MyersBriggs Theory and Inventory, and with students taking a standard MBTI test to determine their own Myers-Briggs Personality Type, course participants are then prepared to engage in an inclass activity that is intended to give participants a sense of how personality can influence political preferences.

With no background discussion, and with participants having already determined (at home) their MBTI type, participants are given five minutes to respond to the following in-class task:

\section{"Observers agree most Native Americans are marginalized in today's America and they have not fully benefitted from the "American Dream." Your task is to} identify 3 actions you would take to bolster the inclusion of Native Americans to into the U.S. mainstream."

The focus on Native Americans and issues of inclusion is straightforward and permits us to consider how course participants might approach the complex challenge of trying to enhance the inclusion of this highly marginalized population. I assume all course participants, including international students, have some awareness of U.S. Native Americans, and further that participants are able to identify a few basic actions as they address Native Americans' marginalized position in the U.S. The task-statement is focused and to-the-point, with the minimalist wording not biasing student responses in any particular direction that might constitute an MBTI Personality Type bias.

Given that we view an individual's MBTI Personality Type as private, we do not ask participants to disclose their MBTI type, though students are free to self-disclose their MBTI type. ${ }^{3}$ But

\footnotetext{
${ }^{2}$ The top 15 perceived friend-states to the United States, in that YouGov survey, include France (\#4), Sweden (\#8), and the Netherlands (\#13), all of whom have been subject to strong political criticism by many Americans (e.g., "unreliable ally France," "socialist Sweden," and "situational [un]ethical Netherlands."

${ }^{3}$ When we have completed our in-class task, we ask students to turn in one summary sheet that has their MBTI type and their suggested policy actions, but that does not have their names. Moreover, we make clear turning in this
} 
participants have their four-letter type in front of them, as they also have their identified three Native American inclusion actions. The invited MBTI specialist organizes the standard 16 MBTI types into a manageable four summary types based on two MBTI dimensions that reflect (1) how individuals acquire information and (2) how individuals make decisions. These two dimensions are key to our intended in-class task. The MBTI specialist then relates these four summary types (ST, NT, SF, NF) to types of actions that could be proposed in response to the task of bolstering the inclusion of Native Americans into the broader American society.

The details and nuances of the MBTI Personality Inventory, with its 16 personality type categories, preclude a developed discussion of each personality type in this paper. But I note here the summary four MBTI types the MBTI specialist developed and that we use in our inclass task, with a brief characterization of each type, and the percentage of students who evince each type:

$\begin{array}{lll}\text { Type } & \text { Type characterization } & \text { Percentage of students } \\ \text { ST } & \text { Practical, matter-of-fact, want to get it right } & 20 \% \text { of students } \\ \text { NT } & \text { Logical, rational, want to understand } & 22 \\ \text { SF } & \text { Friendly, empathetic, want to serve others } & 18 \\ \text { NF } & \text { Personal meaning, self-expression, empowerment } & 40\end{array}$

I note here, in passing, that this population of Pol 209 students varies in MBTI type from the overall U.S. population, as MBTI type breakdowns for the U.S. population are:

$\begin{array}{ll}\text { ST } & 30 \% \\ \text { NT } & 10 \% \\ \text { SF } & 43 \% \\ \text { NF } & 17 \%\end{array}$

While not essential for presenting this in-class exercise, the contrast in the breakdown of MBTI types between the Pol 209 students and the general U.S. population may derive from the reality that the Pol 209 group involves [ever-more-educated] university students, tending to major in the social sciences, whose personalities tend to be more oriented toward comfort (experience) with diversity and social justice, while this student-population may have a related proclivity toward having empathy. Indeed, students who choose to take a course emphasizing themes of diversity, inclusion, and empathy, may well be individuals who are more inclined to exhibit relevant traits and attitudes.

Important for this paper - and at the heart of our class - is tying MBTI types to suggested policy actions in tackling marginalized Native Americans. A pilot survey conducted in the summer before the Pol 209 course was first offered, with 15 individuals who spanned our four summary types completing the Native Americans task, provided insight as the MBTI specialist and course instructor set out predicted policy suggestions for enhancing the inclusion of marginalized Native Americans, organized by the four MBTI personality types. A summary of our in-class results for Pol 209 participants, with the four types and top two suggested policy actions:

summary sheet is voluntary, and any course participant is free not to turn it in. Overall, $95 \%$ of students in attendance turned in their summary sheet, and this was true in both offerings of Pol 209. 
ST (Sensor/Thinker; practical, matter-of-fact; $20 \%$ of students)

- Focus on economic development so reservations can provide goods and services

- Determine whether or not Native American tribes can be both "sovereign nations" and part of the U.S.

NT (Intuitive/Thinker; logical, rational; 22\%)

- Change Columbus Day to Indigenous People's Day (Alaska, Minnesota, South Dakota, and Vermont)

- Raise awareness (through the media) about how Native Americans are marginalized (treated as insignificant) in American society

SF (Sensor/Feeling; empathetic; 18\%)

- Focus on Native Americans as people with real problems, emotions, and dreams

- Find ways to ensure representation of Native Americans in state and federal legislatures

NF (Intuitive/Feeling; empowerment; 40\%)

- Create state-level commissions to open dialogue and being the process of healing from past transgressions against Native Americans

- Provide free college tuition to Native Americans to attend college as well as low cost housing

More than $80 \%$ of the students who participated in this task indicated their suggested policy actions for enhancing inclusion of Native Americans were either the examples set out by the MBTI specialist for their MBTI personality type, or were compatible with the examples provided. A 15-minute question-and-answer with our invited specialist followed the PowerPoint presentation of the four types and example policy actions, with the comments of students during the Q-and-A, and immediately after class, revealing considerable student comfort with the utility of the MBTI both for (1) characterizing an individual's personality and (2) in helping to suggest tendencies in how an individual might approach a policy task. Participants had been asked, in the preceding class session before we discussed the MBTI and review of the Native American inclusion task, to take the MBTI Personality Test and bring their result to class, and $92 \%$ did so.

Upon completion of the MBTI-Native American inclusion in-class task, the course returns to group-level dimensions of diversity and inclusion. The course turns to focus on economic (in)equality and social justice, with attention to Scandinavia, the so-called Nordic model, and discussion of the national case of Sweden. Reviewing the results of using this MBTI-Native American inclusion in-class task in two offerings of Pol 209 (Fall 2019 and Spring 2020), I conclude there is value in setting out an individual-focused discussion and task to help students think about diversity and inclusion at the most basic and personal level: that of the individual, and of themselves as individuals. In the earliest stage of our class, students reflected over the uniqueness of the individual, the reality of our common human diversity as all of us are unique individuals, and the importance of reflecting over inclusion as we consider the importance of bridging across unique individuals in the construction of a more inclusive whole. Moving on in class to Sweden and social justice, juxtaposing Sweden's experience with that of the United 
States, is a good starting point as the course encounters ten additional, quite varied, polities. Meanwhile, in the next weeks and months, various group-level dimensions of diversity and inclusion are addressed, including nationality/race, gender, sexual orientation, and religion. Indeed, the complexities of engaging the Arab countries of the Levant, as well as Iran and Russia, are more easily tackled with the MBTI-Native American inclusion case study having been completed and assessed.

\section{Toward the Global Classroom}

While one of us used the above-discussed individual-level task to engage issues of diversity and inclusion, the other of us focused on international interaction and collaboration in tackling grouplevel diversity and cross-national acceptance. In collaboration with a colleague from the Department of Sociology at the University of West Georgia, UWG Political Science Department faculty proposed "Global Classrooms" as a course that engages UWG students with students at a partner university abroad (Kharkiv National University, Ukraine) through a range of interactive technologies. In the "Global Classrooms" program, participating faculties incorporate a global dimension into their scheduled class as they link their class with that of another international partner institution. Students in both countries can, at the most basic level, become exposed to alternative ideas and perspectives as they together engage on important political topics.

"Global Classrooms" represents one form of virtual, collaborative education where students in different parts of the world can share joint learning experiences in real time. "Global Classrooms" assumes developing a curriculum where instructors and students teach and learn with peers abroad using internet-based technologies for communication. We believe it is an effective way to internationalize learning within the traditional classroom.

Internationalizing education offers important learning outcomes, such as the strengthening of global fluency, seeing and understanding issues from various perspectives, developing cultural competencies and an understanding of one's place in the world, situating knowledge in a broader context, as well as cultivating active leaders and responsible citizens of a global community. Unfortunately, only a small portion of students at our university and here in the United States participate in study abroad courses. Meanwhile, for many students, the educational destinations are in Western Europe or other highly developed countries (e.g., Australia). "Global Classrooms" offers an accessible way to internationalize teaching and learning experiences by combining cross-cultural collaborations with technology, and this approach expands the array of national settings to include a wide array of cross-cultural collaborations.

Our proposed "Global Classrooms" program enables students to embrace the opportunities and challenges of the world today by giving participants firsthand experience with global issues, cultures, and people. As our students engage their international peers, we provide them the tools to better enable working and living in an interconnected world. Our "Global Classrooms" initiative blends, either wholly or in part, the course at UWG with a comparable course at Kharkiv National University using online technology to foster collaboration and facilitate coteaching. Students pay tuition to - and receive credit from - their home university. 
The "Global Classroom" features either a significant international online portion extending for the duration of the course or the choice of connecting digitally for specific topics or modules. It is intended that faculty utilize both synchronous and asynchronous modes of connection.

A "Global Classroom" is specifically designed to link students who have different cultural and geophysical perspectives and experiences. Such linkages can be achieved through:

- Internationalizing the curriculum

- Providing different perspectives regarding fields of study

- Facilitating a cross-cultural experience for students, without having to leave the classroom

- Developing and/or expanding faculty international research agendas

We received a small grant from the university for this project in 2019. We met shortly after being awarded the grant to begin developing a plan for a "virtual study abroad toolkit." Since nonUWG students would not be able to access our online classes, we immediately recognized that the student information management system D2L would not work as a platform for this project. We discovered several possible platforms including Google Sites and Edu Blogs. We needed a technological solution that was both easy to use, free, and widely accessible. Since my colleague was teaching a course with global content in the spring 2019, we decided to pilot our plan in his "Introduction to Global Studies" class. I coordinated with a former colleague at Kharkiv National University, Ukraine, who was teaching the course "Social Changes in Contemporary Societies," and we scheduled a virtual session to take place in the last week of April 2019. We pitched this session as an extra credit opportunity for interested students. Approximately $40 \%$ of the students in "Global Studies" class participated in the extra credit module on the topic of "democracy promotion as a foreign policy." Students watched a short video introduction to the module and read three articles on the subject. We also created a Google Sites page to house all the relevant course resources. We then invited students in both courses to participate in an online discussion forum. Our trial run proved successful as students on both sides of the Atlantic Ocean demonstrated the feasibility and effectiveness of using the technological architecture we had adopted. The virtual classroom idea has received positive feedback from both institutions. We plan to have several more virtual classroom projects in the years to come.

This experience demonstrates that utilizing "global classrooms" as a form of "virtual study abroad" can help to transform students who have limited international experience into "global citizens" with international experience and cross-cultural competences. We are working on developing a more structured full-time international online undergraduate class serving as a virtual alternative to study abroad experience. We conducted a poll among social science majors at the University of West Georgia asking students if they have plans to study abroad. Most of the respondents indicated that they would consider this option. However, most of them mentioned that most of the available study abroad programs in their discipline are hardly affordable for them. When asked about the possibility of being part of the global classroom project, they indicated this option as very interesting and perspective. Our observations and analysis of student-led discussions that were required of students revealed that this experience improved students' substantive knowledge and created a learning environment to develop their skills in cross-cultural open dialogue with virtual classmates. We have discovered that this experience helps the instructor to reach many educational goals, to enhance students' understanding of 
foreign countries and cultures. It also helps students to learn from each other through online communication. The effectiveness of this approach has been demonstrated through the students' post-class feedback and evaluation of the class. Our findings indicate that "Global Classrooms" can help the students learn cross-cultural communication and help them develop skills demanded in a global job market. Our trial also showed that a small-scale virtual study abroad program could be imported into a wide variety of classes.

The biggest challenge in developing our virtual study abroad program has been coordinating class schedules with our colleagues at Kharkiv National University. I believe this schedule coordination issue will also be the biggest impediment to the wider adoption of this program. Over the summer 2019, we met with our collaborator at Kharkiv National University to coordinate the next iteration of "Global Classroom." As classes at Kharkiv National University begin the academic year more than one month after our UWG classes do in the fall and spring, our plan is to once again integrate our "Global Classroom" module into classes which are scheduled to be taught in spring 2020.

A related and equally interesting experience was to encourage our students to interact with students found in other national academic settings through American and foreign students' virtual participation in an international multidisciplinary conference for undergraduate and graduate students organized by the Student Scientific Society of the School of Sociology at Kharkiv National University, Ukraine. Held in March of 2019 at the School of Sociology of V.N. Karazin, Kharkiv National University, the international student conference was attended by students from Ukraine and numerous other countries, including the United States. Interdisciplinary in its nature, the conference brought together students from various disciplines including Political Science. Several UWG students submitted proposals for presentations and were selected to present their student research findings on the virtual panels conducted via Skype. This was an excellent experience for UWG students to share exchange ideas with their Ukrainian and other national peers, with an added benefit being our UWG students having the opportunity to have their papers published in the conference proceedings. As for the students' participation in the International Students Conference, they were able to share their student research findings with their peers abroad. They were excited to get feedback on their findings and to learn about the state of their field of study in other countries. We plan to engage more students into this initiative as part of the Undergraduate Student Research Week in April.

\section{Summary Reflections}

We agree with most educators that the $21^{\text {st }}$ century college-level learning experience should include opportunities for students to engage and reflect over issues of human diversity and inclusion. Our pedagogical approaches can vary, as is evident in the presentation here of our efforts, in two different universities. Indeed, our foci of interest can vary, as one of us uses an individual-level task - and the other relies on a cross-national and cross-classroom learning experience - to foster enhanced student sensitivity to diversity and inclusion.

As our discussions here have indicated, considerable planning and a meaningful commitment of resources (and if only, by "resources," we mean the time and energy of the committed faculty members) are required to seriously engage the important but nuanced realities of diversity and 
inclusion. However, we hope the presentation of our different - yet interconnected - efforts offers encouragement as so many of us continue to tackle, with our students, this central aspect of the human experience. 